\title{
T-cell prolymphocytic leukemia
}

\author{
Joanna Drozd-Sokołowska*, Wiesław Wiktor Jędrzejczak
}

Department of Hematology, Oncology and Internal Diseases, Medical University of Warsaw, Warsaw, Poland

\begin{abstract}
T-cell prolymphocytic leukemia (T-PLL) is a rare mature T-cell lymphoma. The diagnosis of T-PLL is made based on the criteria proposed in 2019 by the T-PLL International Study Group (TPLL-ISG). T-PLL may be diagnosed in an 'active' or an 'inactive' form. While T-PLL is most often characterized by an aggressive clinical course, approximately $20-30 \%$ of patients may have a stable or slowly progressive disease in the initial period. Only the active form requires treatment. The treatment initiation criteria were defined in the consensus proposed by the TPLL-ISG. Data on the effectiveness of various therapeutic approaches comes from small, non-randomized studies. No drug is approved for the treatment of T-PLL. The standard of care in the first line of treatment is intravenous alemtuzumab. Consolidation therapy in eligible patients consists of allogeneic hematopoietic stem cell transplantation, preferably after TBI-based conditioning. In the remaining patients, neither maintenance nor consolidation treatment is recommended. There is no standard therapy for the relapse, although, based on genome studies, many drugs may be potentially effective, including histone deacetylase inhibitors and BCL2 inhibitors.
\end{abstract}

Key words: T-cell prolymphocytic leukemia, T-PLL, TPLL-ISG

Acta Haematologica Polonica 2021; 52, 2: 85-93

\section{Introduction}

T-cell prolymphocytic leukemia is a rare lymphoma derived from mature peripheral T lymphocytes [1]. It was distinguished from chronic lymphocytic leukemia for the first time in 1973 based on the clinical picture, the morphology of the tumor cells, and the poor prognosis [2]. The new entity also included T-cell chronic lymphocytic leukemia, which had been distinguished in previous classifications $[3,4]$. Its incidence is estimated at around 0.6-2 new cases per $1,000,000$ per year $[5,6]$, which is about $2 \%$ of all chronic leukemias. In Poland, no more than 30 cases are diagnosed annually.

T-PLL occurs mainly in older people, with a median age at diagnosis of 60+. Men are affected twice as often as women. The clinical course is usually aggressive. In approximately $20-30 \%$ of patients, T-PLL may develop slowly in the initial stage [7]. The duration of the 'chronic' phase of the disease varies. Despite the initial 'benign' course, almost all patients are expected to progress and die due to the disease.

\section{Pathogenesis}

Genetic changes observed in T-PLL include translocations of proto-oncogenes to the vicinity of constitutively active TCR receptor chain genes (alpha and delta) on chromosome $14 q 11.2$, e.g. $t(14 ; 14)(q 11 ; q 32)$ or $t(X ; 14)(q 28$; q11) or $\operatorname{inv}(14)(q 11 ; q 32)$. The consequence of the resulting genetic lesions is the activation of TCL1 (14q32) or MTCP1 (Xq28) genes. TCL1 gene encodes a TCL1 protein that in vitro modulates the activity of AKT serine-threonine kinases involved in signaling from the TCR receptor. However, these genetic lesions are not sufficient for leukemia transformation. Secondary cytogenetic changes include both amplifications and deletions, including $11 \mathrm{q}$ and ATM

\footnotetext{
*Address for correspondence: Joanna Drozd-Sokołowska, Department of Hematology, Oncology and Internal Diseases, Medical University of Warsaw, Banacha 1a, 02-097 Warsaw, Poland phone: +48 2259928 18, fax: +48 2259914 18, e-mail: joanna.drozd-sokolowska@wum.edu.pl
PTHiT Copyright (c) 2021
The Polish Society of Haematologists and Transfusiologists, Insitute of Haematology and Transfusion Medicine. All rights reserved.


gene as well as chromosomes 8 and 17. The accumulation of various mutations results in complex karyotype observed in the majority of patients [8]. It is generally accepted that TCL1 activation and impaired ATM activity play a key role in the pathogenesis of T-PLL, and the phenotype of T-PLL cells can be described as TCL1 $1^{\text {up }} / \operatorname{ATM}^{\text {def }}[9,10]$.

Unlike in other neoplasms, mutations in the TP53 gene are rarely found in T-PLL. Nevertheless, p53 activation is hampered by ATM deficiency, and in consequence normal, deacetylated p53 remains bound to MDM2 (mouse double minute 2), TP53 inhibitor [9].

Mutations in genes responsible for histone modifications, such as KMT2C, KMT2D, KMT5A, and EZH2 are often observed in T-PLL $[9,11]$. DNA repair is further impaired by the altered expression of genes encoding for components of epigenetic regulation [11].

Chromosome 8 trisomy and iso8q are observed in approximately two in every three patients; in some cases, these lesions may be related to MYC overexpression $[6,12,13]$. JAK and STAT activating mutations are observed in more than $60 \%$ of patients. The most common mutations are single nucleotide variants (SNVs) of JAK3, JAK1, and STAT5B $[11,12,14]$. No mutations are observed in BCL2 gene family [9].

HTLV-1 is not involved in oncogenesis in patients with T-PLL [6].

\section{Clinical presentation}

T-PLL is characterized by rapidly increasing lymphocytosis, most often exceeding $100 \times 10^{9} /$ L. Splenomegaly and hepatomegaly are present at diagnosis in the majority of patients. Lymphadenopathy, skin lesions (skin nodules, rash, rarely erythroderma), peripheral edema, including conjunctival edema and periorbital edema, and pleural and peritoneal effusions are observed in some cases. Central nervous system involvement is possible, although this is rarely observed. Patients often complain of $B$ symptoms $[1,6,15,16]$.

\section{T-PLL diagnostic criteria}

\section{Diagnostic tests}

In 2019, the T-PLL International Study Group (TPLL-ISG) published diagnostic recommendations for T-PLL [8]. According to these, the diagnosis of T-PLL includes cytological evaluation of peripheral blood smear, immunophenotyping, and genetic testing.

The diagnosis of T-PLL is based on the detection of one three morphological variants of clonal prolymphocytes in the peripheral blood or bone marrow. Most often $(75 \%$ of cases), T-PLL cells are medium-sized, with a high nuclear-cytoplasmic ratio, moderately condensed chromatin, single, clearly visible nucleolus, slightly basophilic cytoplasm, and cytoplasmic protrusions. In $20 \%$ of cases, T-PLL cells are small, with condensed chromatin; the nucleolus is invisible by light microscopy. In $5 \%$ of cases, the nucleus resembles the shape of the brain (cerebriform variant). There are no differences in clinical course between the morphological variants. Despite the characteristic features, T-PLL cannot be diagnosed solely on the basis of cell morphology.

Flow cytometry is one of the basic diagnostic tools used to diagnose T-PLL and differentiate it from other neoplasms originating from T cells. T-PLL prolymphocytes express antigens typical for mature T cells, such as CD3, CD5, and CD7, as well as the cytoplasmic TCL1. No expression of CD1a is detected [9]. T-PLL cells can be both $\mathrm{CD}^{+}(\sim 60 \%)$ and $\mathrm{CD}^{+}(\sim 15 \%)$, or they may express both antigens simultaneously ( 25\%) [8]. CD52 is also expressed, and high density of this antigen explains the high sensitivity of T-PLL to alemtuzumab. Antigens such as CD25, CD38, and HLA-DR are expressed with different frequencies, and markers of cytotoxic granules, e.g. TIA-1, are always negative, even in $\mathrm{CD}^{+}$prolymphocytes. The phenotype of prolymphocytes may change during the course of the disease and treatment $[6,15,16]$.

Genetic tests include TCR rearrangement (TRB, TRG) assessment to evaluate cell clonality as well as karyotype and fluorescent in situ hybridization (FISH). Clonal TCR rearrangement evaluation is obligatory in all patients, while other tests are optional and recommended only in specific cases. Approximately $70-80 \%$ of patients have a complex karyotype with repeated cytogenetic lesions, such as $\operatorname{inv}(14)(q 11 q 32), t(14 ; 14)(q 11 ; q 32), t(X ; 14)(q 28 ; q 11)$, missense deletions or mutations within 11q23, idic(8)p11, $\mathrm{t}(8 ; 8)(\mathrm{p} 11-12 ; \mathrm{q12}), 8 \mathrm{q}$ trisomy, and $\operatorname{del}(12 \mathrm{p})$ [8]. These lesions are described in detail in the 'Pathogenesis' section above.

Bone marrow examination is not necessary for diagnosis. Indications for bone marrow examination, as well as for other affected organs biopsy, depend on the clinical situation. In patients from endemic areas, it is necessary to test for HTLV1 infection with serological or polymerase chain reaction (PCR)-based methods.

The diagnosis of T-PLL is made based on major and minor criteria (Table I). The diagnosis of T-PLL is established when all major criteria, or the first two major criteria and at least one minor criterion, are met. In patients with no TCL1A, TCL1B, or MTCP1 rearrangement or overexpression, TCL1-family negative T-PLL is diagnosed.

Differential diagnosis of T-PLL includes other T-cell lymphomas in leukemic phase, including: T-cell acute lymphoblastic leukemia, characterized by the expression of TdT and CD1a, peripheral T-cell lymphoma, not expressing cyTLC1', T-cell large granular lymphocytic leukemia (T-LGL) CD8 ${ }^{+}, \mathrm{CD}^{+} 7^{+}, \mathrm{CD}_{16}{ }^{+}$, Sézary syndrome CD7 ${ }^{-}, \mathrm{CD}^{+}$, $\mathrm{CD} 25^{+}$, and adult T-cell lymphocytic leukemia (ATLL) $\mathrm{CD} 4^{+}$, CD25 $5^{+}$, HTLV$^{+}$. 
Table I. Diagnostic criteria for T-cell prolymphocytic leukemia (T-PLL) according to T-PLL International Study Group (TPLL-ISG) [8]

\section{Major criteria}

1. $>5 \times 10^{9} / \mathrm{L}$ cells with the T-PLL phenotype in the peripheral blood or bone marrow

2. T-cell clonality (determined by TRB/TRG PCR or flow cytometry)

3. Abnormalities of $14 q 32$ or $\mathrm{Xq} 28$ OR expression of TCL1A/B or MTCP1

Minor criteria

1. Chromosome 11 abnormalities (11q22.3;ATM)

2. Chromosome 8 abnormalities: idic(8)(p11), t(8;8), trisomy $8 q$

3. Chromosome 5, 12, 13, and 22 abnormalities or a complex karyotype

4. Involvement of T-PLL specific site (e.g. splenomegaly, effusions)

TRB - T-cell receptor $\beta ;$ TRG - T-cell receptor $y$; PCR - polymerase chain reaction

\section{Prognostic factors}

So far, no prognostic index has been developed for patients with T-PLL, mostly due to the rarity of the disease. In multivariate analysis of 119 patients treated in 1990-2016 published by Jain et al. [17], the following factors negatively affected overall survival (OS): pleural effusion ( $H R=2.08$; 95\% Cl: 1.11-3.9), high LDH activity ( $\geq 1.668 \mathrm{IU} / \mathrm{L})$ (HR $=2.5 ; 95 \% \mathrm{Cl}: 1.20-4.24)$, and low hemoglobin concentration (<9.3 g/dL) (HR =0.33; 95\% Cl: 0.14-0.75).

In the study by Hu et al. involving 97 patients, complex karyotype was associated with a shorter OS compared to the normal karyotype. The authors were not able to demonstrate the prognostic significance of any specific cytogenetic lesions for OS. However, the presence of at least five cytogenetic aberrations was a negative prognostic factor for survival [18]. Similarly, the presence of the JAK3 mutation, as shown by Stengel et al. [19], and high TCL1 expression, as shown by Herling et al, are associated with a poorer prognosis [13].

\section{Indications for treatment initiation; pre-treatment evaluation}

As already mentioned, T-cell prolymphocytic leukemia may initially have a slow course in some patients. There is no data indicating that initiation of treatment at this stage improves long-term outcomes. Therefore, in accordance with the recommendations of the TPLL-ISG, patients do not require any treatment at this stage. Treatment should only be initiated in patients who have active T-PLL, which is defined as having at least one of the treatment initiation criteria presented in Table II. Close monitoring is recommended in patients with inactive T-PLL. This should include a monthly physical
Table II. T-cell Prolymphocytic Leukemia International Study Group (TPLL-ISG) treatment initiation criteria (at least 1 criterion must be met to initiate the treatment) [8]

\begin{tabular}{|c|c|}
\hline \multirow{4}{*}{$\begin{array}{l}\text { Symptoms related } \\
\text { to the disease }\end{array}$} & ECOG performance status $\geq 2$ \\
\hline & $\begin{array}{l}\text { Unintentional weight loss }>10 \% \text { within } \\
6 \text { months }\end{array}$ \\
\hline & $\begin{array}{l}\text { Drenching night sweats, without evi- } \\
\text { dence of infection }\end{array}$ \\
\hline & Fever $>38^{\circ}$, without evidence of infection \\
\hline \multirow{2}{*}{$\begin{array}{l}\text { Symptomatic bone } \\
\text { marrow failure }\end{array}$} & Anemia $(\mathrm{Hb}<10 \mathrm{~g} / \mathrm{dL})$ \\
\hline & Thrombocytopenia (PLT <100 ×10\% $/ \mathrm{L}$ ) \\
\hline \multirow{2}{*}{$\begin{array}{l}\text { Rapidly progressing } \\
\text { lymphadenopathy, } \\
\text { splenomegaly, and } \\
\text { hepatomegaly }\end{array}$} & $\begin{array}{l}>50 \% \text { in } 2 \text { months; doubling in diame- } \\
\text { ter }<6 \text { months }\end{array}$ \\
\hline & $\begin{array}{l}\text { Symptomatic enlargement of the } \\
\text { lymph nodes, spleen, or liver }\end{array}$ \\
\hline \multirow{2}{*}{$\begin{array}{l}\text { Increasing lympho- } \\
\text { cytosis }\end{array}$} & If $>30 \times 10^{9} / \mathrm{L}:>50 \%$ in 2 months \\
\hline & $\begin{array}{l}\text { Lymphocyte doubling time in less than } \\
6 \text { months }\end{array}$ \\
\hline \multirow[t]{3}{*}{ Extranodal disease } & Organ infiltration \\
\hline & Pleural or peritoneal effusion \\
\hline & Central nervous system involvement \\
\hline
\end{tabular}

ECOG - Eastern Cooperative Oncology Group; Hb - hemoglobin; PLT - platelets

examination and complete blood count. The TPLL-ISG treatment initiation criteria are set out in Table II [8]. These recommendations also cover relapsed T-PLL.

Before treatment initiation, all patients require evaluation according to Cumulative IIIness Rating Scale (CIRS), Eastern Cooperative Oncology Group (ECOG) performance status, and computed tomography of the neck, chest, abdomen, and pelvis. PET/CT examination is not currently recommended, although there are reports suggesting the usefulness of this examination in these patients [20]. As is the case with other lymphomas, it is necessary to determine the activity of lactate dehydrogenase (LDH) and the virological status of the patient (HBV, HCV, HIV, HSV).

\section{Therapy}

Due to the very low incidence of T-PLL, data on treatment efficacy comes from small, non-randomized studies. Evaluating treatment efficacy is further complicated by the different diagnostic and response criteria used by different authors [8]. However, we know for certain that T-cell prolymphocytic leukemia is resistant to conventional chemotherapy [6, 21]. For these reasons, other treatments for T-PLL have been sought.

The first improvement in the treatment outcome was associated with the use of purine nucleoside analogues. The response rate in pentostatin-treated patients was 45\%, 
while the complete remission rate was $9 \%$, with a median progression-free survival (PFS) of 6 months and OS of 9 months [22]. Another breakthrough was related to the use of alemtuzumab. Dearden et al. [23] showed that administration of alemtuzumab in a group of previously treated patients induced response in $76 \%$, including $60 \%$ of complete remission and $16 \%$ of partial remission. Unfortunately, the combined use of alemtuzumab and pentostatin did not translate into outcome improvement as compared to alemtuzumab monotherapy [24].

\section{First-line treatment}

Alemtuzumab, a humanized anti-CD52 monoclonal antibody, is currently recommended as first-line treatment for T-PLL. As with other monoclonal antibodies, the mechanism of action is based on the induction of antibody-dependent cellular cytotoxicity, complement-dependent cytotoxicity, and direct induction of cell death [25]. Alemtuzumab is used at the standard dose, i.e. $30 \mathrm{mg}$ three times a week intravenously over 10-12 weeks. Alemtuzumab induces response in $91 \%$ of patients, including $81 \%$ of complete remission (CR). There are no recommendations regarding treatment prephase in patients with high baseline tumor mass. Therapeutic leukapheresis should be considered. A study comparing the efficacy of intravenous and subcutaneous alemtuzumab was prematurely discontinued due to a very low response rate in the subcutaneous arm (33\%) and a high percentage of deaths in this patient group [26]. It seems that this phenomenon is caused by the slower achievement of the desired antibody concentration in serum after subcutaneous administration. Lack of response after subcutaneous administration of the antibody may be also caused by the formation of neutralizing antibodies against alemtuzumab [27, 28]. Median progression-free survival in patients treated with alemtuzumab ranges from 7-12 months, as summarized in the study by Braun et al. [29].

The use of alemtuzumab in combination with chemotherapy does not improve the effectiveness of the treatment compared to intravenous alemtuzumab monotherapy. A German group analyzed the effectiveness of the two protocols $F M C+A$ and $F M C A+A$ in phase II clinical trials [30, 31]. For the $F M C+A$ protocol, the authors initially used four cycles of FMC [fludarabine $25 \mathrm{mg} / \mathrm{m}^{2}$ intravenous (i.v.) on days $1-3$, mitoxantrone $8 \mathrm{mg} / \mathrm{m}^{2}$ i.v. on day 1 , cyclophosphamide $200 \mathrm{mg} / \mathrm{m}^{2}$ on days 1-3], followed by treatment consolidation with alemtuzumab i.v. for up to 12 weeks. Response rate after FMC was 68\%, and the addition of alemtuzumab increased this to $92 \%$. Median OS of patients treated with FMC-A was 17.1 months, and progression-free survival was 11.9 months. The most frequently observed adverse events included hematological complications and CMV infection reactivation. In the FMCA+A protocol, subcutaneous alemtuzumab was administered from the very beginning of the treatment $[10 \mathrm{mg}$ subcutaneous (s.c.) days 1-3 in cycles 1-2, 30 mg s.c. days 1-3 in cycles 3-4 in the absence of CR after two cycles] together with FMC at the following doses: fludarabine $20 \mathrm{mg} / \mathrm{m}^{2}$ i.v. on days $1-3$, mitoxantrone $6 \mathrm{mg} / \mathrm{m}^{2}$ i.v. on day 1 , cyclophosphamide $200 \mathrm{mg} / \mathrm{m}^{2}$ on days $1-3$. Maintenance with alemtuzumab was provided for one year in patients not eligible for allogeneic hematopoietic stem cell transplantation (allo-HSCT) (30 mg s.c. once a month in months 1-6, and another $30 \mathrm{mg}$ in months 9 and 12). In the group of previously untreated patients analyzed per protocol, the response rate was $75 \%$. Median progression-free survival for the entire patient population (13 treatment-naïve, 5 FMCA-A in the second-line) in the intent-to-treat (ITT) analysis was 7.5 months, and in the analysis of actually treated patients (per protocol) 11.2 months. The authors highlighted that the side effects of chemotherapy made it impossible to maintain the appropriate intensity of the treatment with alemtuzumab, and therefore reduced the effectiveness of the therapy.

The administration of bendamustine in the first-line of treatment allows a response to be obtained only in $67 \%$ of patients, with a short response duration of 2-10 months [32]. Therefore, bendamustine is not recommended at this stage. It is worth noting however that the use of bendamustine is associated with relatively low toxicity. Therefore, in a group of carefully selected patients with severe comorbidities or in the case of alemtuzumab intolerance, its use may be exceptionally considered.

In patients with an unsatisfactory response to alemtuzumab (persistent high tumor mass, persistent high number of leukemic cells), an increase in the frequency of alemtuzumab administration or the addition of a purine nucleoside analogue, most often fludarabine or pentostatin, may be considered [29, 33].

There is no data on maintenance treatment with alemtuzumab after completion of induction therapy containing alemtuzumab, hence this treatment is not currently recommended. However, a study on the use of romidepsin in maintenance therapy is currently ongoing (NCT02512497).

When using alemtuzumab, it is important to prevent Pneumocystis jiroveci and Herpesviridae (HSV, CMV) infections. Regular CMV monitoring in the blood is essential, ideally by quantitative PCR testing. CMV reactivation may affect up to $50 \%$ of patients [29].

Currently, central nervous system involvement prophylaxis is not recommended. There are no systematic reports on the treatment of CNS involvement. According to the experts, it is necessary to use intrathecal cytostatics e.g. a three-drug protocol containing methotrexate, cytarabine, and a glucocorticosteroid or systemically administered methotrexate in doses that ensure penetration into the CNS [15]. In a report by Alsawah et al. [34], the intrathecal administration of alemtuzumab was effective. 
It is worth mentioning that alemtuzumab is not available in Poland for hematological indications. According to the regulations of the Ministry of Health and Social Welfare, this drug is available only via target import. In addition to submitting the target import application, it is necessary to contact Clinigen to register, and then complete the form sent by the company. This can be done by telephone on +44 (0) 1283494340 (fax +44 (0) 1283494 341) or by e-mail: customer.services@clinigengroup.com. The drug is delivered to the pharmacy by the Komtur company.

\section{Consolidation treatment}

Allo-HSCT used in the consolidation of the induction treatment is the recommended therapeutic procedure in younger patients in good general condition without significant comorbidities. This means that this procedure can be performed only in 30-50\% of patients [29].

In the first published study involving a large group of patients, Krishnan et al. [35] analyzed 28 patients, including 13 treated with allo-HSCT and 15 undergoing autologous hematopoietic stem cell transplantation (auto-HSCT). All had previously received alemtuzumab. Comparison of the transplant results with the historical control group of patients who achieved complete remission after treatment with alemtuzumab and survived at least 6 months showed increased OS from 20 months in the control group to 33 months in the allo-HSCT group, and to 48 months in the entire group of patients who underwent any hematopoietic stem cell transplantation. The authors did not observe any differences in OS between the patients undergoing allo- and auto-HSCT [35].

In a retrospective EMBT analysis of 41 patients transplanted before 2007, it was found that after allo-HSCT, 3-year OS was 21\% (95\% Cl: 7-34\%) while 3-year relapse-free survival was (RFS) 19\% (95\% Cl: 6-31\%). The 3-year incidences of relapse (RI) and non-relapse mortality (NRM) were both $41 \%$. Most relapses were observed in the first year after allo-HSCT. The use of total body irradiation (TBI) for conditioning as well as early transplantation (less than one year from diagnosis) were associated with longer relapse-free survival. It should be remembered, however, that patients in complete or partial remission constituted only $56 \%$ of the group, while patients previously treated with alemtuzumab made up 24\% [36]. In the prospective EBMT analysis performed between 2007 and 2012, the results of elective transplantation were evaluated in 37 patients without T-PLL progression. In this group, 4-year progression-free survival was 30\% (95\% Cl: 14-46), and 4-year OS was $42 \%$ (95\% Cl, 25-49). The 4-year RI and NRM were $38 \%$ (95\% Cl: $22-55)$ and 32\% (95\% Cl: 16-47), respectively. In univariate analysis, only whole body irradiation at a dose of 6 Gy or higher was associated with a lower risk of relapse, and time from diagnosis to allo-HSCT of less than 12 months with lower non-relapse mortality [37].
More data on the efficacy of allotransplantation of hematopoietic cells was published in a French study involving 27 patients. In this group, 3-year OS was 36\% (95\% Cl: 17-54\%), while the 3-year PFS was 26\% (95\% Cl: 14-45\%). Relapses were mainly observed during the first 24 months, with a median time to relapse of 11.7 months. The 3-year NRM was $31 \%$. Patients with response to the induction therapy constituted the majority of the group (89\%) [38].

To summarize the data on allo-HSCT in patients with T-PLL, recently a gradual improvement in the prognosis of these patients has been observed. However, long-term survival is achieved in less than $50 \%$ of patients. Treatment failure can be caused by both relapse of the disease and non-relapse mortality.

Effective consolidation therapy in patients not eligible for allo-HSCT has not yet been identified. For this reason, consolidation and maintenance treatments are not used in this group of patients.

\section{Treatment of relapse}

Relapse is expected in all T-PLL patients who have not undergone allo-HSCT, as well as in a high percentage of transplanted patients. Treatment options in relapse are very limited. Provided that alemtuzumab has not been used before, alemtuzumab therapy seems justified in relapse. This option can also be used in patients with late relapse, i.e. after at least 6 months of remission. In these cases, it is necessary to confirm CD52 expression on the surface of the T-PLL cells. It should be remembered that CD52 expression should not be evaluated in bone marrow immunohistochemistry due to the high rate of false negative results [29]. In patients for whom alemtuzumab seems unjustified, purine nucleoside analogues or possibly bendamustine, optimally at a dose of $120 \mathrm{mg} / \mathrm{m}^{2}$ for the first two days of the 21-day cycle, should be administered [15, 32].

\section{New therapeutic possibilities}

Due to constantly improving understanding of the pathogenesis of T-PLL and the ability to identify potential molecular targets, it seems that targeted drugs such as histone deacetylase inhibitors (HDACs), EZH1/2 inhibitors, and p53-reactivating drugs, e.g. MDM2 inhibitors, JAK/STAT pathway inhibitors, CDK inhibitors, PI3K inhibitors (copanlisib, duvelisib) [9-11, 39, 40], or venetoclax could be effective in the treatment of relapse.

Venetoclax, HDAC inhibitors, and JAK inhibitors have already been used in patients with refractory T-PLL. The use of venetoclax in two patients with refractory T-PLL allowed for partial remission in both [41] and combined treatment with pentostatin and venetoclax resulted in a complete remission lasting 10 months [16]. In patients refractory to 
Table III. Definition of response after treatment according to T-cell Prolymphocytic Leukemia International Study Group (TPLL-ISG) [8]

\begin{tabular}{|c|c|c|c|c|}
\hline Groups & $\begin{array}{l}\text { Complete remission } \\
\text { (CR) }\end{array}$ & $\begin{array}{l}\text { Partial remission } \\
\text { (PR) }\end{array}$ & $\begin{array}{l}\text { Stable disease } \\
\qquad(\mathrm{SD})^{* * * *}\end{array}$ & $\begin{array}{l}\text { Progressive disease } \\
\text { (PD) }\end{array}$ \\
\hline & All criteria met & $\begin{array}{l}\text { At least } 2 \text { criteria from group } \\
\qquad A \text { and at least } \\
1 \text { criterion from group B met }\end{array}$ & All criteria met & $\begin{array}{l}\text { At least } 1 \text { criterion from } \\
\text { group } A \text { or } B \text { met }\end{array}$ \\
\hline \multicolumn{5}{|l|}{ GROUP A } \\
\hline Lymph node size* & $\begin{array}{l}\text { In the long-axis } \\
\text { diameter }<1.0 \mathrm{~cm}\end{array}$ & SLD reduction by $\geq 30 \%$ & $\begin{array}{l}\text { A reduction of less } \\
\text { than } 30 \% \text { or an } \\
\text { increase of no more } \\
\text { than } 20 \%\end{array}$ & $\begin{array}{l}\text { SLD increase by } \\
>20 \% * * * * *\end{array}$ \\
\hline Spleen dimension & $<13 \mathrm{~cm}$ & $\begin{array}{c}\text { A reduction of } \geq 50 \% \\
\text { in vertical length beyond } \\
\text { normal from baseline }\end{array}$ & $\begin{array}{l}\text { A change of no more } \\
\text { than } 49 \% \text { beyond } \\
\text { normal from baseline }\end{array}$ & $\begin{array}{l}\text { An increase of } \geq 50 \% \text { in } \\
\text { the vertical length beyond } \\
\text { normal from baseline }\end{array}$ \\
\hline $\begin{array}{l}\text { Constitutional } \\
\text { symptoms }\end{array}$ & Absent & Any & Any & Any \\
\hline $\begin{array}{l}\text { Peripheral blood } \\
\text { lymphocytes count }\end{array}$ & $<4 \times 10^{9} / \mathrm{L}$ & $\begin{array}{c}\leq 30 \times 10^{9} / \mathrm{L} \text { and a decrease } \\
\text { of } \geq 50 \% \text { from baseline }\end{array}$ & $\begin{array}{c}>30 \times 10^{9} / \mathrm{L} \text { or no } \\
\text { more than } 49 \% \\
\text { change from baseline }\end{array}$ & $\begin{array}{c}\text { An increase of } \geq 50 \% \text { from } \\
\text { baseline }\end{array}$ \\
\hline Bone marrow & $\begin{array}{l}\text { T-PLL cells }<5 \% \text { of } \\
\text { mononuclear cells }\end{array}$ & $\begin{array}{l}\text { Any result other than complete } \\
\text { remission }\end{array}$ & Any & Any \\
\hline $\begin{array}{l}\text { Involvement of any } \\
\text { specific site** }\end{array}$ & None & Any & Any & Any \\
\hline \multicolumn{5}{|l|}{ GROUP B } \\
\hline Platelet count & $\begin{array}{l}\geq 100 \times 10^{9} / \mathrm{L} \\
\text { (untransfused) }\end{array}$ & $\begin{array}{c}\geq 100 \times 10^{9} / \mathrm{L} \text { or } \geq 50 \% \text { increase } \\
\text { from baseline } \\
\text { (untransfused) }\end{array}$ & $\begin{array}{l}\text { No more than } 49 \% \\
\text { change from baseline }\end{array}$ & $\begin{array}{l}\text { A decrease of } \geq 50 \% \\
\text { from baseline }\end{array}$ \\
\hline $\begin{array}{l}\text { Hemoglobin } \\
\text { concentration }\end{array}$ & $\begin{array}{c}\geq 11 \mathrm{~g} / \mathrm{dL} \\
\text { (untransfused; } \\
\text { independant of ESAs) }\end{array}$ & $\begin{array}{l}\geq 11 \mathrm{~g} / \mathrm{dL} \text { or } \geq 50 \% \text { increase } \\
\text { from baseline (untransfused; } \\
\quad \text { independant of ESAs) }\end{array}$ & $\begin{array}{c}<11 \mathrm{~g} / \mathrm{dL} \text { or }<50 \% \\
\text { change from baseline } \\
\text { or less than } 2 \mathrm{~g} / \mathrm{dL} \\
\text { change }\end{array}$ & $\begin{array}{l}\geq 2 \mathrm{~g} / \mathrm{dL} \text { decrease } \\
\text { from baseline }\end{array}$ \\
\hline Neutrophil count & $\begin{array}{l}\quad \geq 1.5 \times 10^{9} / \mathrm{L} \\
\text { (independant of } \\
\text { granulocyte colony } \\
\text { stimulating factors) }\end{array}$ & $\begin{array}{c}\geq 1.5 \times 10^{9} / \mathrm{L} \text { or } \geq 50 \% \text { increase } \\
\text { from baseline } \\
\text { (independant of granulocyte } \\
\text { colony stimulating factors) }\end{array}$ & $\begin{array}{l}\text { Change by no more } \\
\text { than } 49 \%\end{array}$ & $\begin{array}{c}\text { A decrease of } \geq 50 \% \text { from } \\
\text { baseline }\end{array}$ \\
\hline
\end{tabular}

*Assessed for lymph nodes with a long axis diameter $\geq 1.5 \mathrm{~cm}$ before the initiation of treatment; assessment should be performed using computed tomography (CT) or magnetic resonance imaging (MRI): $* *$ pleural effusion, peritoneal effusion, infiltrates in the skin, central nervous system; ***if initially only one parameter was incorrect, only that one parameter needs to be improved; ****stable disease is diagnosed only after it persists for at least 3 months; *****for small lymph nodes $<1.5 \mathrm{~cm}$ it is necessary to increase the diameters by $5 \mathrm{~mm}$ and the long-axis diameter to $1.5 \mathrm{~cm}$; $S L D-$ sum of the long-axis diameters of the 3 target lesions ; ESAs - erythropoiesis stimulating agents

alemtuzumab monotherapy, the combination of HDAC with cladribine and alemtuzumab was effective [42], whereas treatment with JAK inhibitors (tofacitinib, ruxolitinib) was associated with only moderate efficacy [43].

Based on the results of in vitro studies, it seems that combined treatment with bendamustine and HDAC inhibitors including tinostamustine, which is a compound resulting from the combination of bendamustine and vorinostat, could also be effective [44]. Tinostamustine is currently being tested in clinical trials (NCT02576496). Similarly, the combination of venetoclax and ibrutinib that sensitizes T-PLL cells to venetoclax via ITK pathway (IL-2 inducible T cell kinase), could improve the efficacy of the treatment [45]. A phase II trial evaluating such a combination in alemtuzumab-refractory patients was started in 2019 (NCT03873493). Disappointing results in in vitro studies were obtained for poly-ADP-ribose polymerase (PARP) inhibitors [10], despite significant premises suggesting their effectiveness in this indication [46].

After the initial success of chimeric antigen receptor T-leukocytes (CAR-T) in cancer treatment, the use of immunotherapy in T-PLL is broadly discussed. Unlike in B-cell lymphoid neoplasms, it is difficult to identify the target for CAR-T cells in T-PLL. The use of CAR-T against an antigen commonly found on T lymphocytes is unacceptable, as this would lead to aplasia of T lymphocytes and, consequently, severe immune disorders. According to this concept, Maciocia et al. [47] produced CAR-T cells 
directed against TRBC1 (TCR beta-chain constant 1), that selectively targeted T-PLL cells expressing this domain, and saved healthy T-cells with the TRBC2 domain. The experiments were performed both in vitro and in an animal model. There is no data on the use of CAR-T in this indication in humans.

\section{Treatment response evaluation}

Response to treatment should be assessed according to the criteria proposed by the TPLL-ISG [8]. Due to the fact that different treatments have different expected response durations, the timing of the response assessment should be individualized for each patient and the type of treatment being administered.

The response should be evaluated based on two groups of parameters: group A for general symptoms and parameters that are a direct indicator of tumor mass, and group $B$ for the effect of T-PLL cells on hematopoietic cells. Criteria for the evaluation of imaging diagnostics in T-PLL have not been developed so far. Until such criteria are developed, the iwCLL criteria for chronic lymphocytic leukemia [48] or the Lugano criteria for lymphomas [49] can be used. Due to the simplicity of the assessment, the TPLL-ISG proposes the use of the RECIL criteria [50] in which, unlike the RECIST criteria, only three target lesions are assessed, summing up their length in one dimension.

Response criteria are presented in Table III.

In complete remission (CR), it is necessary to exclude splenomegaly and hepatomegaly by physical examination. If all criteria for complete remission from group $A$ are met, and at least one criterion from group $B$ is not met, complete remission with incomplete hematological recovery (CRi) is diagnosed. The diagnosis of $\mathrm{CR}$ and $\mathrm{CRi}$ requires confirmatory bone marrow examination, including aspirate and histopathological examination. However, this examination, similarly to imaging diagnostics, should be performed only after achieving the response, as evaluated in the complete blood count. For $\mathrm{CR}$, it is not necessary to exclude minimal residual disease (MRD).

Stable disease is diagnosed in patients who do not achieve at least partial remission and who do not show evidence of disease progression, as long as it persists for at least three months.

In T-PLL progression, the deterioration of peripheral blood count parameters must directly result from bone marrow involvement by the T-PLL infiltration. It is necessary to exclude the toxicity of the drugs, as well as autoimmune cytopenia. In uncertain cases, bone marrow examination may be necessary.

The objective response rate (ORR) is defined as the percentage of patients achieving one of the following responses: CR, CRi, or partial remission (PR). In turn, the best objective response is defined as the best response maintained for at least four weeks with continuous treatment, and for at least eight weeks with intermittent treatment.

The authors of the recommendations advocate the introduction of the term 'disease control rate', which would include CR, CRi, partial remission (PR) and stable disease (SD), as well as the term 'disease control time'.

TPLL-ISG recommendations [8] also define the endpoints that should be assessed for T-PLL, such as: PFS, event-free survival (EFS), time to next treatment, OS, relapse, refractory disease and treatment failure, and finally MRD.

\section{Follow-up after treatment and obtaining remission}

After the treatment is completed and remission is obtained, follow-up visits should take place every 4-6 weeks and should include physical examination, $\mathrm{CBC}$, and biochemical tests.

\section{Conclusions}

T-cell prolymphocytic leukemia is a very rare disease of the lymphoid system with an unfavorable prognosis. Despite the increasing efficacy of the therapeutic approaches, long-term disease control can only be achieved with allogeneic hematopoietic stem cell transplantation, and only in selected patients. Current reports show that the results of transplantation are significantly improved, as long as the patients referred for transplantation are in complete remission after alemtuzumab treatment. Undoubtedly, it is necessary to seek new therapeutic methods, especially for patients not eligible for allo-HSCT or in relapse. Due to the rarity of the disease, multi-center collaboration is necessary.

\section{Authors' contributions}

JDS - fundamental contribution to concept and design, collation of literature, approval of final version for publication. WWJ - critical review for significant intellectual content, acceptance of final version for publication.

\section{Conflict of interest}

None.

\section{Financial support}

None.

\section{Ethics}

The work described in this article has been carried out in accordance with The Code of Ethics of the World Medical Association (Declaration of Helsinki) for experiments involving humans; EU Directive 2010/63/EU for animal experiments; Uniform Requirements for Manuscripts submitted to Biomedical Journals. 


\section{References}

1. Swerdlow SH, Campo E, Pileri SA, et al. The 2016 revision of the World Health Organization classification of lymphoid neoplasms. Blood. 2016; 127(20): 2375-2390, doi: 10.1182/blood-2016-01-643569, indexed in Pubmed: 26980727.

2. Catovsky D, Okos A, Wiltshaw E, et al. Prolymphocytic leukaemia of B and T cell type. The Lancet. 1973; 302(7823): 232-234, doi: 10.1016/s0140-6736(73)93135-8.

3. Hastrup N, Hamilton-Dutoit S, Ralfkiaer E, et al. Peripheral T-cell lymphomas: an evaluation of reproducibility of the updated Kiel classification. Histopathology. 1991; 18(2): 99-105, doi: 10.1111/j.13652559.1991.tb01451.x, indexed in Pubmed: 2010191.

4. Harris NL, Jaffe ES, Stein H, et al. A revised European-American classification of lymphoid neoplasms: a proposal from the International Lymphoma Study Group. Blood. 1994; 84(5): 1361-1392, indexed in Pubmed: 8068936.

5. Herling M, Khoury JD, Washington LT, et al. A systematic approach to diagnosis of mature T-cell leukemias reveals heterogeneity among WHO categories. Blood. 2004; 104(2): 328-335, doi: 10.1182/ /blood-2004-01-0002, indexed in Pubmed: 15044256.

6. Matutes E, Brito-Babapulle V, Swansbury J, et al. Clinical and laboratory features of 78 cases of T-prolymphocytic leukemia. Blood. 1991; 78(12): 3269-3274, indexed in Pubmed: 1742486.

7. Garand R, Goasguen J, Brizard A, et al. Indolent course as a relatively frequent presentation in T-prolymphocytic leukaemia. Groupe Français d'Hématologie Cellulaire. Br J Haematol. 1998; 103(2): 488-494, doi: 10.1046/j.1365-2141.1998.00977.x, indexed in Pubmed: 9827924.

8. Staber PB, Herling M, Bellido M, et al. Consensus criteria for diagnosis, staging, and treatment response assessment of T-cell prolymphocytic leukemia. Blood. 2019; 134(14): 1132-1143, doi: 10.1182/ /blood.2019000402, indexed in Pubmed: 31292114.

9. Schrader A, Braun T, Herling M. The dawn of a new era in treating T-PLL. Oncotarget. 2019; 10(6): 626-628, doi: 10.18632/oncotarget.26595, indexed in Pubmed: 30774758.

10. Schrader A, Crispatzu G, Oberbeck S, et al. Actionable perturbations of damage responses by TCL1/ATM and epigenetic lesions form the basis of T-PLL. Nat Commun. 2018; 9(1): 697, doi: 10.1038/s41467017-02688-6, indexed in Pubmed: 29449575.

11. Kiel MJ, Velusamy T, Rolland D, et al. Integrated genomic sequencing reveals mutational landscape of T-cell prolymphocytic leukemia. Blood. 2014; 124(9): 1460-1472, doi: 10.1182/blood-2014-03-559542, indexed in Pubmed: 24825865.

12. Bergmann AK, Schneppenheim S, Seifert M, et al. Recurrent mutation of JAK3 in T-cell prolymphocytic leukemia. Genes Chromosomes Cancer. 2014; 53(4): 309-316, doi: 10.1002/gcc.22141, indexed in Pubmed: 24446122.

13. Herling M, Patel KA, Teitell MA, et al. High TCL1 expression and intact T-cell receptor signaling define a hyperproliferative subset of T-cell prolymphocytic leukemia. Blood. 2008; 111(1): 328-337, doi: 10.1182/ /blood-2007-07-101519, indexed in Pubmed: 17890451.

14. Wahnschaffe L, Braun T, Timonen S, et al. JAK/STAT-activating genomic alterations are a hallmark of T-PLL. Cancers (Basel). 2019; 11(12), doi: 10.3390/cancers11121833, indexed in Pubmed: 31766351.

15. Dearden C. How I treat prolymphocytic leukemia. Blood. 2012; 120(3): 538-551, doi: 10.1182/blood-2012-01-380139, indexed in Pubmed: 22649104.
16. Chen $\mathrm{X}$, Cherian S. Immunophenotypic characterization of T-cell prolymphocytic leukemia. Am J Clin Pathol. 2013; 140(5): 727-735, doi: 10.1309/AJCPG71KYOXTKLQW, indexed in Pubmed: 24124154.

17. Jain $P$, Aoki $E$, Keating $M$, et al. Characteristics, outcomes, prognostic factors and treatment of patients with T-cell prolymphocytic leukemia (T-PLL). Ann Oncol. 2017; 28(7): 1554-1559, doi: 10.1093/annonc/ /mdx163, indexed in Pubmed: 28379307.

18. Hu Z, Medeiros $\sqcup$, Fang L, et al. Prognostic significance of cytogenetic abnormalities in T-cell prolymphocytic leukemia. Am J Hematol. 2017; 92(5): 441-447, doi: 10.1002/ajh.24679, indexed in Pubmed: 28194886.

19. Stengel A, Kern W, Zenger M, et al. Genetic characterization of T-PLL reveals two major biologic subgroups and JAK3 mutations as prognostic marker. Genes Chromosomes Cancer. 2016; 55(1): 82-94, doi: 10.1002/gcc.22313, indexed in Pubmed: 26493028.

20. Alfayez $M$, Thakral $B$, Jain $P$, et al. First report of clinical response to venetoclax combination with pentostatin in T-cell-prolymphocytic leukemia (T-PLL). Leuk Lymphoma. 2020; 61(2): 445-449, doi: 10.1080/10428194.2019.1660967, indexed in Pubmed: 31566032.

21. Catovsky D. Prolymphocytic leukaemia. Nouv Rev Fr Hematol. 1982; 24: 343-347.

22. Mercieca J, Matutes E, Dearden C, et al. The role of pentostatin in the treatment of T-cell malignancies: analysis of response rate in 145 patients according to disease subtype. J Clin Oncol. 1994; 12(12): 2588-2593, doi: 10.1200/JC0.1994.12.12.2588, indexed in Pubmed: 7989933.

23. Dearden $\mathrm{CE}$, Matutes $\mathrm{E}$, Cazin $\mathrm{B}$, et al. High remission rate in T-cell prolymphocytic leukemia with CAMPATH-1H. Blood. 2001; 98(6): 1721-1726, doi: 10.1182/blood.v98.6.1721, indexed in Pubmed: 11535503.

24. Ravandi F, Aribi A, O'Brien S, et al. Phase II study of alemtuzumab in combination with pentostatin in patients with T-cell neoplasms. J Clin Oncol. 2009; 27(32): 5425-5430, doi: 10.1200/JC0.2009.22.6688, indexed in Pubmed: 19805674.

25. Zhao Y, Su H, Shen $X$, et al. The immunological function of CD52 and its targeting in organ transplantation. Inflamm Res. 2017; 66(7): 571-578, doi: 10.1007/s00011-017-1032-8, indexed in Pubmed: 28283679.

26. Dearden CE, Khot A, Else M, et al. Alemtuzumab therapy in T-cell prolymphocytic leukemia: comparing efficacy in a series treated intravenously and a study piloting the subcutaneous route. Blood. 2011; 118(22): 5799-5802, doi: 10.1182/blood-2011-08-372854, indexed in Pubmed: 21948296.

27. Montagna M, Montillo M, Avanzini MA, et al. Relationship between pharmacokinetic profile of subcutaneously administered alemtuzum$\mathrm{ab}$ and clinical response in patients with chronic lymphocytic leukemia. Haematologica. 2011; 96(6): 932-936, doi: 10.3324/haematol.2010.033159, indexed in Pubmed: 21330330.

28. Hale G, Rebello P, Brettman LR, et al. Blood concentrations of alemtuzumab and antiglobulin responses in patients with chronic lymphocytic leukemia following intravenous or subcutaneous routes of administration. Blood. 2004; 104(4): 948-955, doi: 10.1182/ /blood-2004-02-0593, indexed in Pubmed: 15090452.

29. Braun T, von Jan J, Wahnschaffe L, et al. Advances and perspectives in the treatment of T-PLL. Curr Hematol Malig Rep. 2020; 15(2): 113-124, doi: 10.1007/s11899-020-00566-5, indexed in Pubmed: 32034661.

30. Hopfinger G, Busch R, Pflug N, et al. Sequential chemoimmunotherapy of fludarabine, mitoxantrone, and cyclophosphamide induction followed by alemtuzumab consolidation is effective in T-cell prolymphocytic leukemia. Cancer. 2013; 119(12): 2258-2267, doi: 10.1002/ /cncr.27972, indexed in Pubmed: 23512246. 
31. Pflug N, Cramer P, Robrecht $\mathrm{S}$, et al. New lessons learned in T-PLL: results from a prospective phase-II trial with fludarabine-mitoxantrone-cyclophosphamide-alemtuzumab induction followed by alemtuzumab maintenance. Leuk Lymphoma. 2019; 60(3): 649-657, doi: 10.1080/10428194.2018.1488253, indexed in Pubmed: 30234404.

32. Herbaux C, Genet P, Bouabdallah $\mathrm{K}$, et al. Bendamustine is effective in T-cell prolymphocytic leukaemia. Br J Haematol. 2015; 168(6): 916-919, doi: 10.1111/bjh.13175, indexed in Pubmed: 25316212.

33. Cross M, Dearden C. B and T cell prolymphocytic leukaemia. Best Pract Res Clin Haematol. 2019; 32(3): 217-228, doi: 10.1016/j. beha.2019.06.001, indexed in Pubmed: 31585622.

34. Alsawah F, Benitez L, Choi S, et al. Intrathecal alemtuzumab: a potential treatment of refractory leptomeningeal T-cell prolymphocytic leukemia. Blood Adv. 2019; 3(21): 3333-3336, doi: 10.1182/bloodadvances.2019000289, indexed in Pubmed: 31698446.

35. Krishnan B, Else M, Tjonnfjord GE, et al. Stem cell transplantation after alemtuzumab in T-cell prolymphocytic leukaemia results in longer survival than after alemtuzumab alone: a multicentre retrospective study. Br J Haematol. 2010; 149(6): 907-910, doi: 10.1111/j.13652141.2010.08134.x, indexed in Pubmed: 20201944.

36. Jedrzejczak WW, Dearden C, de Wreede L, et al. EBMT Chronic Leukemia Working Party. Hematopoietic stem cell transplantation in T-prolymphocytic leukemia: a retrospective study from the European Group for Blood and Marrow Transplantation and the Royal Marsden Consortium. Leukemia. 2012; 26(5): 972-976, doi: 10.1038/leu.2011.304, indexed in Pubmed: 22116553.

37. Jedrzejczak WW, Drozd-Sokolowska J, Eikema DJ, et al. EBMT prospective observational study on allogeneic hematopoietic stem cell transplantation in T-prolymphocytic leukemia (T-PLL). Bone Marrow Transplant. 2019; 54(9): 1391-1398, doi: 10.1038/s41409-0190448-x, indexed in Pubmed: 30664723.

38. Guillaume T, Beguin Y, Tabrizi R, et al. Allogeneic hematopoietic stem cell transplantation for T-prolymphocytic leukemia: a report from the French society for stem cell transplantation (SFGM-TC). Eur J Haematol. 2015; 94(3): 265-269, doi: 10.1111/ejh.12430, indexed in Pubmed: 25130897.

39. Andersson El, Pützer S, Yadav B, et al. Discovery of novel drug sensitivities in T-PLL by high-throughput ex vivo drug testing and mutation profiling. Leukemia. 2018; 32(3): 774-787, doi: 10.1038/leu.2017.252, indexed in Pubmed: 28804127.

40. Ito Y, Makita S, Tobinai K. Development of new agents for peripheral T-cell lymphoma. Expert Opin Biol Ther. 2019; 19(3): 197-209, doi: 10.1080/14712598.2019.1572746, indexed in Pubmed: 30658046.

41. Boidol B, Kornauth C, van der Kouwe E, et al. First-in-human response of BCL-2 inhibitor venetoclax in T-cell prolymphocytic leukemia. Blood. 2017; 130(23): 2499-2503, doi: 10.1182/blood-2017-05-785683, indexed in Pubmed: 28972014.
42. Hasanali ZS, Saroya BS, Stuart A, et al. Epigenetic therapy overcomes treatment resistance in T cell prolymphocytic leukemia. Sci Transl Med. 2015; 7(293): 293ra102, doi: 10.1126/scitransImed.aaa5079, indexed in Pubmed: 26109102.

43. Gomez-Arteaga A, Margolskee E, Wei MT, et al. Combined use of tofacitinib (pan-JAK inhibitor) and ruxolitinib (a JAK1/2 inhibitor) for refractory T-cell prolymphocytic leukemia (T-PLL) with a JAK3 mutation. Leuk Lymphoma. 2019; 60(7): 1626-1631, doi: 10.1080/10428194.2019.1594220, indexed in Pubmed: 30997845.

44. Pützer S, Varghese L, von Jan J, et al. Reinstated p53 response and high anti-T-cell leukemia activity by the novel alkylating deacetylase inhibitor tinostamustine. Leukemia. 2020; 34(9): 2513-2518, doi: 10.1038/s41375-020-0772-6, indexed in Pubmed: 32099034.

45. Kornauth CF, Herbaux C, Boidol B, et al. The combination of venetoclax and ibrutinib is effective in relapsed/refractory T-prolymphocytic leukemia and influences BCL-2-family member dependencies. Hematol Oncol. 2019; 37: 482-484, doi: 10.1002/hon.161_2631.

46. Weston VJ, Oldreive CE, Skowronska A, et al. The PARP inhibitor olaparib induces significant killing of ATM-deficient lymphoid tumor cells in vitro and in vivo. Blood. 2010; 116(22): 4578-4587, doi: 10.1182/ /blood-2010-01-265769, indexed in Pubmed: 20739657.

47. Maciocia PM, Wawrzyniecka PA, Philip B, et al. Targeting the T cell receptor $\beta$-chain constant region for immunotherapy of T cell malignancies. Nat Med. 2017; 23(12): 1416-1423, doi: 10.1038/nm.4444, indexed in Pubmed: 29131157.

48. Hallek M, Cheson BD, Catovsky D, et al. iwCLL guidelines for diagnosis, indications for treatment, response assessment, and supportive management of CLL. Blood. 2018; 131(25): 2745-2760, doi: 10.1182/blood-2017-09-806398, indexed in Pubmed: 29540348.

49. Cheson BD, Fisher RI, Barrington SF, et al. Alliance, Australasian Leukaemia and Lymphoma Group, Eastern Cooperative Oncology Group, European Mantle Cell Lymphoma Consortium, Italian Lymphoma Foundation, European Organisation for Research, Treatment of Cancer/Dutch Hemato-Oncology Group, Grupo Español de Médula Ósea, German High-Grade Lymphoma Study Group, German Hodgkin's Study Group, Japanese Lymphorra Study Group, Lymphoma Study Association, NCIC Clinical Trials Group, Nordic Lymphoma Study Group, Southwest Oncology Group, United Kingdom National Cancer Research Institute. Recommendations for initial evaluation, staging, and response assessment of Hodgkin and non-Hodgkin lymphoma: the Lugano classification. J Clin Oncol. 2014; 32(27): 3059-3068, doi: 10.1200/JC0.2013.54.8800, indexed in Pubmed: 25113753.

50. Younes A, Hilden P, Coiffier B, et al. International Working Group consensus response evaluation criteria in lymphoma (RECIL 2017). Ann Oncol. 2017; 28(7): 1436-1447, doi: 10.1093/annonc/mdx097, indexed in Pubmed: 28379322. 